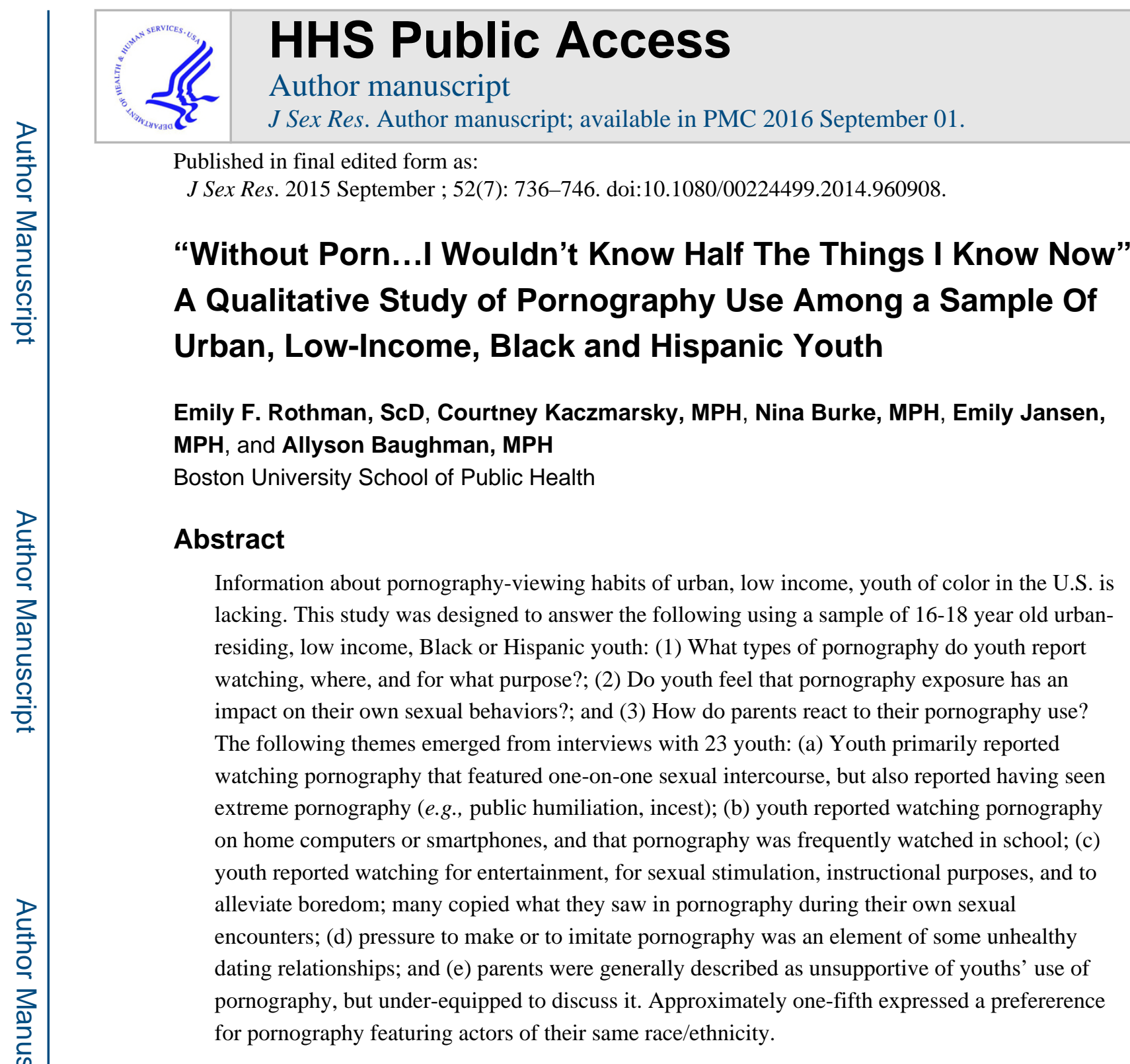

\title{
Keywords
}

Pornography; Sexually explicit material; Adolescent health; Sexual health; Health disparities

Nationally representative data indicate that $23 \%$ of U.S. youth ages $10-15$ years old have purposefully sought out sexually explicit material (SEM; also called X-rated material, erotica, porn or pornography) in the past year (Ybarra, Mitchell, Hamburger, Diener-West, $\&$ Leaf, 2011). By the time U.S. youth are 14 years old, $66 \%$ of males and $39 \%$ of females have viewed either print, film or internet pornography at least once in the past year, either on purpose or incidentally (Brown \& L'Engle, 2009). Although it has been argued that adolescents are likely particularly susceptible to being influenced by pornography because of their developing sexual identities and biologically-based "criticial period" of development, and their relative sexual inexperience (Peter \& Valkenburg, 2011; Pfaus et al., 2012; Sinkovic, Stulhofer, \& Bozic, 2013), the scientific evidence on whether viewing SEM has an effect on adolescent or emerging adults' sexual behavior is mixed. On the one hand, a number of studies have found exposure to SEM is associated with a higher number of 
overall and casual sexual partners, online sexual harrassment, earlier age of sexual debut, less sexual and relationship satisfaction, sexually permissive attitudes, a tendency to view women as sexual objects, and higher preferences for sexual practices typically presented in SEM (Braun-Courville \& Rojas, 2009; Brown \& L'Engle, 2009; Jonsson, Priebe, Bladh, \& Svedin, 2014; Morgan, 2011; Peter \& Valkenburg, 2009; Peter \& Valkenburg, 2011).

However, other studies have found only weak or no association between SEM exposure and adolescents' or young adults' sexual behavior (Hald, Kuyper, Adam, \& de Wit, 2013; Luder et al., 2011; Sinkovic et al., 2013; Stulhofer, Jelovica, \& Ruzic, 2008).

A clear limitation of the existing body of knowledge related to youth pornography use is that the majority has been conducted using samples of college students (Carroll et al., 2008;

Morgan, 2011; Olmstead, Negash, Pasley, \& Fincham, 2013), or outside the U.S., including, for example, in Croatia, the Czech Republic, Greece. Hong Kong, Indonesia, the Netherlands, Sierra Leone, Sweden, and Switzerland (Day, 2014; Hald et al., 2013; LofgrenMartenson \& Mansson, 2010; Luder et al., 2011; Ma \& Shek, 2013; Mulya \& Hald, 2014; Sinkovic et al., 2013; Tsitsika et al., 2009). The results of these studies may not be generalizable to non-college-attending or U.S. youth, because it has been established that adolescent sexual behavior varies by nation, age, gender, and culture (Baumgartner, Sumter, Peter, Valkenburg, \& Livingstone, 2014; Brown \& L'Engle, 2009; Brown et al., 2006; Eisenman \& Dantzker, 2006; Hald et al., 2013; Meston \& Ahrold, 2010). Thus, there have been calls for additional information about U.S. adolescent pornography use (Smith, 2013), and for pornography research from more diverse populations of adolescents (LofgrenMartenson \& Mansson, 2010).

Low-income Black and Hispanic youth are priorty populations for public health research (Koh, Graham, \& Glied, 2011), in part because they are at increased risk for sexually transmitted infections (STIs), unplanned pregnancies, and risky sexual behavior (Dariotis, Sifakis, Pleck, Astone, \& Sonenstein, 2011; Deardorff et al., 2013; Finer \& Zolna, 2011; Kaplan, Jones, Olson, \& Yunzal-Butler, 2013). Whether and how exposure to pornography could be a factor in these health disparities is unknown. There is presently almonst no information about whether there are disparities in U.S. youths' pornography use by race, although one nationally-representative study of online pornography exposure among youth found no difference by race (Wolak, Mitchell, \& Finkelhor, 2007). However, a longitudinal study of 1,017 youth from the Southeastern U.S. found that Black youth were dispoportionately more likely to have used any pornography in the past year as compared to White youth (Brown \& L'Engle, 2009), and similarly, among adults age 18 years and older, analyses of the General Social Survey (GSS) have found that non-Whites are more likely to consume pornography than Whites, and that this difference in pornography consumption has widened over time (Wright, 2013; Wright, Bae, \& Funk, 2013).

\section{Objectives and Research Questions}

The present paper was designed to provide insight into the pornography use experiences of low income, urban, youth of color in the U.S., who have been underrepresented in pornography research to date. The research questions driving this inquiry were as follows. Among a sample of 16-18 year old youth who have viewed pornography in the past year: (1) 
what types of pornography do they report watching, where, and for what purpose?; (2) do they feel that pornography exposure has an impact on their own sexual behaviors?; and (3) what kind of interactions do they have with their parents about pornography? To our knowledge, this is the first study to undertake answering these questions using a sample of urban youth of color.

\section{Theoretical Framework}

Our research was guided by sexual script theory and research (Gagnon \& Simon, 2005;

Sakaluk, Todd, Milhausen, \& Lachowsky, 2014). This theory suggests that sexual behavior is in part governed by social influences, and that humans enact beliefs about their own and others' sexuality by internalizing sets of norms about what is or is not sexually arousing (Lofgren-Martenson \& Mansson, 2010). In addition, our research is grounded in neuroscientific explanations for how sexual interests in humans are formed, such as the ideas that adolescence is a critical period for developing and crystallizing sexual interests, that sexual arousal cues may form after a single exposure to a stimulus in males, and that sexual responsiveness can be formed in response to cued and uncued interests reinforced by orgasm (Baumeister, 2000; Ogas \& Gaddam, 2011; Pfaus et al., 2012). Moreover, we drew upon behavioral science research that has demonstrated that exposure to sexual media can influence youth attitudes, normative pressure, and self-efficacy, which in turm impact their sexual behavior (Bleakley, Hennessy, Fishbein, \& Jordan, 2008; Bleakley, Hennessy, Fishbein, \& Jordan, 2011). Taken together, these concepts suggest that there may be both biological and social reasons that adolescent sexuality and sexual behavior may be impacted by what they view in pornography.

\section{Methods}

Sample

A convenience sample of youth was recruited from the pediatric emergency department of a large, urban, SafetyNet hospital located in Boston, MA. The patient population at this hospital is $60 \%$ Black, $15 \%$ Hispanic, $15 \%$ White, $2 \%$ Asian, and $8 \%$ multi-racial or another race; $>80 \%$ are living in poverty. The emergency department setting was used because it was convenient and resource-efficient for the investigators (Rothman, Linden, Baughman, Kaczmarsky, \& Thompson, 2013). The participants in this study were $60 \%$ female, $47 \%$ Black, 43\% Hispanic, and 8\% Multiracial (N=23) (Table 1).

To be eligible for the study, patients had to be between 16-18 years old, medically stable, able to communicate in English, a resident of Boston, and had to report having seen pornography at least once in the past year either intentionally or unintentionally. Minors who were unaccompanied by an adult were permitted to assent to participate in the study without additional parental consent being obtained. All procedures were approved by the Institutional Review Board (IRB) at the Boston University School of Public Health.

The procedure for recruiting participants was as follows: A trained research assistant (RA) would scan the emergency department computer system for a patient within the appropriate age range. The RA would then approach that patient's room and invite him/her to participate 
in a research study about pornography. Those who expressed interest in participating were asked to complete an eligibility survey, and those who were eligible were provided with details about participation and asked for assent. Those who assented were then interviewed for approximately 30 minutes by the RA. In cases where parents or others had accompanied the patient, those individuals were asked to wait outside until the interview was over. In total, 188 potential participants were identified through the computer system, of these 133 (71\%) were approached and asked if they might like to screened for eligibility, of these 100 $(75 \%)$ were screened, and 39 (39\%) were eligible.

\section{Interview procedures}

Trained RAs conducted and audio-recorded the interviews. Interviews were conducted using a standardized protocol (i.e., list of open-ended questions), and additional follow-up questions were asked when clarification was needed. Participants were assured that their interviews would be kept confidential, and RAs were trained to ask questions in a way that was non-judgmental and not leading. At the outset of the interviews, participants were informed that the word "pornography" would be used to refer to sexually explicit or x-rated material that features partially or fully naked people engaged in sexual acts.

\section{Data analysis}

The semi-structured interview began with basic questions about the participant in order to establish a rapport. Information about experiences with pornography was elicited by asking a series of questions about when the participant had first viewed pornography, most recently viewed pornography, the context for these viewings and any regular viewings, which websites the participant visited, and which categories of pornography they were most likely to select when they visited websites with menus that allow the user to select a type of video. Each interview was coded for themes related to what participants watched, when, with whom, why, and what their parents' responses to their pornography use were, if the parents were aware.

The coding process was as follows: (1) three individuals (authors NB, EJ and CK) read through each transcript in order to get "a sense of the whole" (Sandelowski, 1995); (2) these three authors, in consultation with the study principal investigator (author ER), generated a coding list, where codes represented a theme that emerged from the interview data; and (3) codes were applied to sections of text by two independent coders (NB, EJ or CK). The coders then met to review their coding decisions, and to record how many sections of text they had coded similarly (i.e., inter-rater reliability). The inter-rater reliability was $95 \%$. Where discrepancies existed, the two coders discussed their decisions until consensus on a code was reached. In order to improve the chances that the two coders would make similar coding decisions on all analyzed texts, at the outset of the process they used four interview texts to practice their coding and harmonize their decisions.

Once all interviews were coded, the data were explored in-depth using the qualitative software analysis program Atlas.ti (ATLAS.ti, 1999). First, members of the research team conducted searches by code, and looked at each section of text to which a particular code had been applied to get a sense of the thematic responses within that coding category. 
Second, all members of the research team met to discuss the themes that emerged from the text and to select illustrative quotations that represented each.

\section{Results}

\section{What are they watching?}

All adolescents in this sample reported watching pornography for free and online. Two had watched pornographic videos and/or cable television, but none described viewing pornographic books or magazines. Specific websites that were mentioned by numerous participants included Youporn, Redtube, and Pornhub. Participants reported watching a number of different subgenres of pornography, and most often reported that they watched pornography featuring heterosexual intercourse or women having sex with women, but they also reported having watched pornography that featured incest, rape and bestiality. Several mentioned that they had seen pornography featuring bondage, bukkake (i.e., multiple men ejaculating onto one woman's face), group sex, choking, and public humiliation-and while a few females expressed distate and surprise, the general reaction to these more extreme forms of pornography was indifference or acceptance. Five participants-two males and three females--mentioned that they or their partners always preferred to watch pornography that featured people of their same race or ethnicity (e.g., Black, Hispanic). Males generally provided less detail about the pornography that they had viewed. The following exchange (with an 18 year old male) was typical:

Interviewer: What websites do you go to?

Participant: I don't have any specific [one]. Just whatever I [google].

Interviewer: Do you click on any particular type of pornography?

Participant: Uh, I just usually stay with, like, straight.

However, several females in the sample provided more detailed descriptions of what they had seen, particularly clips that stood out to them as surprising. For example, a 17-year-old female commented:

It's called public humiliation. Which means they tie the girl up, say on the statue or pole or something. Then they strip them down naked and a guy or girl will embarrass them in public. But the person wants it, so they ask for it...so they're, like, forced to do things like give head or even if they haven't did it in the butt before, they have to, cause they asked for it.

Similarly, an 18-year-old female described the genre of pornography called "rape porn" that she had seen as follows:

Like, basically they had her in this room, this dirty mattress on the floor, she was laying on the mattress and then, like, six different guys keep goin' back and forth. She just layin' there. And then after, they was bein' mean to her, they was throwin' all her clothes at her, tellin' her to get out and stuff.

One 18-year-old female described watching pornography that featured violence, which may have been consensual (e.g., BDSM). Regardless of whether the pornography actors had 
consented, the images of violence were discomfiting to her. She described the video clip this way:

[I saw] men slap girls in their mouth, like in their faces, or like, open up their mouths when they're doing back shots...like slapping them on their boobs, like slapping, like that would hurt me. Yeah, they just do crazy things.

\section{Where do they find pornography and how are they gaining access?}

Youth in this sample reported watching pornography online at home, and at school on desktop computers and smartphones. They reported that they were able to access free pornography on the Internet easily even when they were less than 18 years old. Surprisingly, several $(n=3)$ reported that visiting non-pornographic websites that featured particular celebrities led them to pornography sites in which that celebrity was featured. For example, a 17 -year-old female reported:

[I am] only interested [in porn] when I know [the] people, like the celebrities. Like, there is so much celebrities out there that you think they're so good, and in reality, you type in their name and they have a porn site.

Similarly, an 18-year-old female described a time that she had intended to listen to the music of a recording artist, but due to pornography links on that artist's website, got diverted to watch pornography:

[If you visit] Google, and if you type in '[NAME],' she's a rapper but she's also a porn star. They have links on the side [of her website] with like porn pics and like stuff like that...I wanted to listen to her music, and then oh I kinda got sidetracked.

Many youth described watching pornography in school during school hours. Several also described experiences when a group was watching pornography together in school, and the negative way in which that impacted the classroom environment. For example, a 17-year-old female described an incident when in-school pornography-watching lead to her sexual harassment, self-defensive use of violence, and ultimately her expulsion from school:

Some guys just open up the porn [site], and then they just start watchin' it. And then like the boys start like slapping girls butts, grabbing their boobs and stuff. And actually one time this dude, this one time in tenth grade, this dude, he kept going like that to me, he kept reachin' for my boob and then um I smacked him. Like really hard. And then he hit me back and I started punchin' him and then I got expelled.

A different 17-year-old female explained:

I've actually watched pornography in school, to be honest with you. We all huddle up on one computer (laughs), and then it's so funny because, we all huddle up on one computer and then the girls, they get in the mood in the class with the boys, and the boys start smacking ass and stuff like that. That actually happens.

When asked how it was possible for students to watch pornography at school, she replied:

It's blocked but so many people know how to unblock it. There is like this proxy website. $\mathrm{Mm} \mathrm{hm}$. That's how they unblock...like, ok this one dude he put it on the 
computer, right, and everybody goes to the back of the computers where the teacher can't see nothin'. Like the last computers in the back. That's where everybody goes. And then that's when they start unblockin' websites.

A 17-year-old male reported:

When I used to go to school, I used to go on porn sites sometimes, ya know? Cause I knew my boys, whenever we went to computer class or whatever, they knew like how to, to get on Facebook, to get on everythin'. So we could have really done everythin', everythin' we wanted. Go on a website, whatever.

\section{Why do they watch pornography?}

Youth reported that they watched pornography for a variety of reasons, including that pornography is entertaining and a solution for loneliness and boredom (e.g., "just I got 5 minutes to kill", "I just be bored sometimes."), and for sexual gratification (e.g., "because I'm horny", "because my girlfriend has her period", "when I wanna have sex", "to bust a nut.”). One 17 year old male summarized his motivations in the following way:

Yeah, I'm bored, or to be honest with you, sometimes I'm horny and ya know, there's really no one around for that I'd call, to be honest with you. So I just ya know, masturbate.

Almost every participant $(\mathrm{n}=21)$ reported learning how to have sex by watching pornography. Specifically, they reported that from pornography they had learned sexual positions, what opposite sex partners might enjoy sexually, and to learn how to engage in particular sex acts (e.g., oral sex, anal sex). Both males and females reported learning about sex from pornography (i.e, seven males and 14 females), although females offered more concrete examples of things that they learned.

An 18-year-old female reported:

Without porn, I wouldn't know the positions, I wouldn't know half the things I know now. I never knew even in health class, biology class, everything I'd gone through, that the female body has an ability to "squirt."

Another 17-year-old female explained that she learned how to perform oral sex by watching pornography:

I never knew how to like, suck dick, basically, and I went on there to see, how to do it. And that's how I learned.

Similarly, an 18-year-old male explained he watched pornography in order to learn how to perform oral sex, talk during sex, and initiate sex:

Um probably how to eat a girl out. Um, um, like what to say, I guess. Like different things to say. Um, and how to start it, I guess.

Participants were specifically asked how they thought their own lives were impacted by pornography, if at all. The main theme that emerged, particularly from females, was that in their opinions, watching pornography caused them to engage in sex acts that they would not have tried otherwise. For example, a 17-year-old female said: 
I think anal. It was weird, cause then it hurt me to see [someone] get it back there. I didn't like it (laughs)...It was surprising that someone could do that, I thought that that's where you use the bathroom, that's not where you put something in.

Also, recounting learning anal sex from pornography, a 17-year-old female described trying it herself after viewing it and getting hurt:

What shocked me is how those females can take anal sex. I tried it once. I seen how the woman and stuff is so, they look like they get an orgasm from it. But when I tried it, I was so stunned, like, I ended up getting ibuprofens (sic) and stuff because I was in so much pain.

An 18-year-old female articulated that she learned to make specific sounds during sex by watching pornography, though she was a virgin herself at the time of viewing:

So like during the movie...she was moaning and making all these sounds. So I was like, I need to try that. Like I was serious...I seen a lot of movies that do that, and this was before [I had sex], so I was just like, I need to try that.

Finally a 17-year-old male articulated why he imitates what he sees in pornography in real life:

If I watch porn and, like, I see a male porn star, and sometimes like, if I'm with a female, I try to do the exact same thing as they're doing, 'cause I figure that they're stars.

\section{Does pornography influence youth to use unhealthy relationship behavior?}

Although few youth in this sample reported having any negative experiences with partners as a result of watching pornography, there were two who described ways that pornography played a role in unhealthy relationship behavior (i.e., potentially coercive sexual behavior), and others who described facing pressure from boyfriends to perform acts first seen in pornography. For example, one 17-year-old male, inspired by amateur pornography he viewed, described a time when he used his smartphone to videotape himself having sex with his girlfriend without her consent:

At this time we was together [as partners], so she really couldn't tell me no, ya know? I mean, she could of, cause ya know, but I don't think she would have told me no. Just because, ya know, I was her boyfriend and if I wanted to take a video... ya know?

The respondent went on to explain that the smartphone he used to record the video was eventually lost, and thus may have been viewed by others. Another male, 18-years-old, also described making videos of himself having sex. He explained that it is not unusual for friends to share such sex videos in a casual manner, even in public places like a subway car. It is not clear that the females consented to being filmed, nor to having the videos distributed. Moreover, if the females were younger than 18 when filmed, the males were technically producing, distributing and possessing child pornography.

Me and my buddy, you know, we make videos of our own, and then like one time, my boy made a video, so we was on the train, it was like quiet and he just, he 
turned it up like real loud, and all you hear is the girl moaning, and everybody was just looking. It was his video, just stuff like that, like, you know, we watch it and like, nobody's ashamed of it.

A 17-year-old female commented that she often faced pressure from her boyfriend to watch porn and to imitate it, but she had thus far been able to refuse him successfully:

He likes [ponrography]. He been telling me to do most of the things, but I don't. I'm like, if you don't like how I satisfy you, then go find you a lady that does porn!

Similarly, an 18-year-old female mentioned that she and her boyfriend had experimented with new sexual positions that they saw in pornography, with negative consequences:

[The position is] with me laying down on my stomach and him laying down on top of me. It often, um I know it is kind of extreme, but, it feels like rape. Like, I don't know (laughs). I just feel like I can't move. I feel like even if he's not being rough or anything on me, I just feel like stuffed, like it's not right. I feel like that's something that, it just doesn't, it just doesn't feel like...it's not comfortable. Yeah, it doesn't feel like that's what couples do (laughs). It feels like I'm being forced. I don't like it.

One 17-year-old male said that watching pornography made him uncomfortable because he felt that it encouraged degradation of females. He also explained that he "didn't want to" watch pornography, but that he did it because "it was there":

I don't think porn is helpful...I think it's really degrading to both men and women. And I don't think that it should be there, but it was a resource that I had, so I took it. Um, I didn't want to do it, but you know, since you know, it was there, I did it, so...it makes a woman seem less than what she is. And it's like, they call her slut, bitch, take this and that, and I don't think that's really, you know, nice to say. So I wouldn't recommend it, but it was there, so I took it.

\section{What do parents say?}

Respondents were asked whether their parents knew that they watched pornography, and if so, how they reacted to it. The preponderance of comments about participants' parents' perspectives on pornography coalesced around the notion that parents generally discourage the youths' pornography use, but did not talk about why youth should not use pornography, and were generally uncomfortable with the topic. Many youth also revealed that they were aware of their parents' pornography use, and suspected that their parents' use of pornography was a factor in their reluctance to be too negative about it with their children. For example, one 18-year-old male said:

My Mom and my Mom's boyfriend have a lot of dirty movies, and one time I used a few, and they knew I took them. So they was [just] like, "Oh don't be using our dirty movies."

A 17-year-old male reported that his parents were strict about pornography use when he was 11 or 12 years old, but became less strict as he got older. He described being scolded by his father for watching pornography as an early adolescent: 
Well lately they don't really say nothin', but when I was like 12 , maybe 11 or 12 , they used to be on me for that. They didn't want me to watch it. One of the times they caught me...my father was like,... "Oh if I catch you again lookin' at this stuff, I'm gonna take your iPod away."

An 18-year-old female provided a clear example of the difficult position that parents may find themselves in. According to her, her mother did not want to discuss pornography with her pre-pubescent son, but at the same time felt compelled to discourage him from using it. She said:

[My mother], she tries to not talk to [my younger brother] about it, but give him ways to know what he is doing, he shouldn't be doing at his age. Cause he's only 11-years-old.

\section{Discussion}

To our knowledge, this is the first study to investigate pornography-viewing experiences and habits of a sample of low income, urban-residing, Black and Hispanic youth. Several themes were generated, including (a) that youth had seen a wide range of subgenres of pornography, (b) that youth had easy, free access to online pornography both at home and in school, (c) that youth watched pornography for several reasons, but almost every participant reported learning how to have sex by watchng pornography, (d) pressure to make or to imitate pornography may be an element of some unhealthy dating relationships; and (e) parents of youth in this sample were generally described as unsupportive of youths' use of pornography, but also under-equipped to discuss it with them.

While participantsr reported that they preferred pornography featuring one-on-one sexual intercourse, youth had also unintentionally or intentionally viewed a wide range of specialized and in some cases illict pornography, which has been true for other samples of adolescents (Gonzalez-Ortega \& Orgaz-Baz, 2013). Several female participants and one male expressed discomfort at seeing females raped, hit, hurt, and called insults like "bitch." However, the overall feeling among the individuals in this sample was that pornographyeven in extreme forms--is an unremarkable facet of daily life, which mirrors the findings of a study of pornography use among Swedish youth (Lofgren-Martenson \& Mansson, 2010). Of note is that several participants commented that their favorite musical artists also made pornography, that pornography stars are often used to promote club openings or other special events, and that they would like to be in pornography because it is lucrativesignalling that pornography is considered more glamorous than shameful.

Perhaps unsurprisingly, youth in this sample reported having easy access to internet pornography at home and on their personal electronic devices (e.g., phones). We did not anticipate that the experience of viewing pornography on school property, during class, and with peers would be so commonly reported. It could be that in-school pornography viewing occurs more often than expected in resource-challenged schools because there are fewer faculty available to monitor personal electronic device use or update technology that blocks youths' access to illicit websites. Of concern is that multiple youth in this sample reported that classmates started "smacking ass" and grabbing females' breasts immediately after 
watching pornography in the classroom, and in one instance, fist-fighting. While there is no question that schools are likely doing all that they can to block student access to pornography, it may be useful for educators to know that pornography may be contributing to a sexualized school climate that facilitates harrassment. At the very least, the results of this study clearly demonstrate that some youth are able to access pornography in school despite the U.S. Children's Internet Protection Act (CIPA), which requires that schools receiving Universal Service Administrative Company (USAC) funding have technology protections in place to prevent such access.

In addition, the study highlighted that some youth use pornography as an intructional resource-youth sought out pornography in order to learn how to have sex, others either imitated or were asked by a partner to imitate, what they saw. Our finding that youth imitate what they see in pornography is consistent with at least one prior study of 51 pornographyviewing youth who reported that they copied what they saw in pornography when they had sex (Smith, 2013), and a quantitative study that found that $63 \%$ of a sample of college students reported learning new sexual techniques from pornography (Trostle, 2003). In the present study using pornography as a model for sexual activity had negative consequences for some females in the sample who reported being "stunned" by pain from anal sex, feeling forced to have sex in an uncomfortable position, not enjoying sex, or faking sexual response. These results are consistent with those reported by Marston and Lewis (2014), who found that in a sample of 130 youth ages 16-18 years old, women reported finding anal sex painful, but were often "badgered" into having it by male partners, and that youth felt that interest in anal sex is primarily attributable to pornography (Marston and Lewis, 2014).

There are two primary reasons to worry about the potential impact of pornography on adolescents; first, that the sexual scripts that the majority (55\%) of free adult internet websites present promote hypermasculinity, male domination and the prioritization of male sexual pleasure as the norm (Gorman, Monk-Turner, \& Fish, 2010), and second, that youth will niavely attempt to recreate sexual scenes from pornography that are acted, physically uncomfortable or injurious, or unrealistic (e.g., expecting all women to have orgasms from anal sex). This study was not designed to explore the origins of the sexual scripts of the youth whom were interviewed, however, it did find that several participants had imitated pornography and, in their own view, experienced negative consequences. Thus, our finding supports the emerging evidence that there are instances when sexually explicit material can and does influence adolescent sexual behavior adversely (Bleakley et al., 2008; BraunCourville \& Rojas, 2009; Brown \& L'Engle, 2009; Day, 2014; Hald et al., 2013; Hussen, Bowleg, Sangaramoorthy, \& Malebranche, 2012; Jonsson et al., 2014).

Whether pornography exacerbates coercion or abuse in dating and sexual relationships between youth is unknown. This study provides a starting point for further investigation of this topic. One male in this sample reported that he had filmed sex with his girlfriend without her knowledge or consent with his phone, and another reported that he and his friends routinely share homemade pornography videos with one another in public places. Three females in the sample reported that their boyfriends had pressured them to do things that they had seen in pornography, which is consistent with prior research that found $11 \%$ of a sample of female community health clinic patients reported the same (Rothman et al., 
2012). In sum, the ubiquity of pornography on the internet and proliferation of "tube" websites where users post their own amateur videos may be increasing the likelihood that minors create sexually explicit material, exploit sexual partners, disseminate sexually explicit images of underage peers, and pressure their dating partners to engage in sexual acts that could hurt or upset them. This hypothesis should be tested through larger-scale, quantitative research.

In general, the parents of youth in this sample gave mixed messages about pornography. Although select youth were reprimanded for using pornography at young ages (e.g., 11-13 years old), others reported that their parents were tolerant of pornography use because they were older. Youth reported that in some cases their parents wanted to discourage pornography use but avoided talking about it directly. Some youth reported that they saw or heard their parents watching pornography, and this seemed to normalize pornography use for them. One U.K.-based study found that $16 \%$ of parents who have children that go online once a week or more believe that their children have viewed internet pornography (Livingstone \& Bober, 2004), and research has demonstrated that parental inattention to children's internet use influences the likelihood that they will view sexually explicit websites (Noll, Shenk, Barnes, \& Haralson, 2013). Parents who earn less income and work multiple jobs may have a decreased capacity to monitor their children's internet activities, and this may increase the likelihood that the children are exposed to pornography. If adolescent exposure to pornography contributes to risky sexual behavior, pornography may moderate the relationship between parental monitoring and negative sexual and reproductive health outcomes in youth.

An unanticipated finding of this study was that a number ( 21\%) of Black and Hispanic youth in this sample expressed preferences for viewing pornography featuring Black and Hispanic actors, respectively. This finding is consistent with statistics presented by the pornhub.com website, which reports that "ebony" and "Black" are popular pornography search terms in the Southern states and any cities with a large percentage of Black/AfricanAmerican residents, such as Detroit (Pornhub.com, 2014). Pornhub also reports that searches for "Asian" pornography are prevalent in cities with large Asian subpopulations, such as San Francisco and Honolulu. The idea that youth may be seeking out racially- and ethnicallyspecific pornography is important, because the cues for arousal that may most strongly reinforce subsequent sexual risk behavior as normative could be more acute in these subgenres. As Ogas and Gaddam describe in their 2011 book A Billion Wicked Thoughts, pornography that features Black men typically depict them as particularly powerful and masculine, and they are "frequently perceived as more dominant" than men of other races in pornography (Ogas \& Gaddam, 2011). It has also been argued that "notions of Latin(o) identity have been caricatured and heavily troped" in U.S.-made pornography, and that Black and Latina women are depicted as more hypersexual in pornography than women of other races (Brooks, 2010; Miller-Young, 2010; Subero, 2010). Thus, there is a need to test the hypothesis that Black and Hispanic youth prefer pornography that features actors of their own race and/or ethnicity, that these pornographies are more hyperbolic in their stereotypical presentations of gender roles, and that these representations influence the sexual scripts of Black and Hispanic youth in ways that place them at increased risk for 
risky sexual attitudes, behaviors, and ultimately negative sexual and reproductive health outcomes.

Consistent with prior research, we found that youth in this sample generally appeared to enjoy being asked about this topic and spoke unreseverdly about it (Lofgren-Martenson \& Mansson, 2010). However, males were more reticent; less likely to elaborate on their responses, supplied fewer details, and offered substantially less interpretation or selfreflective insight about their consumption of sexually explicit material than did the females. The difficulties of encouraging discursive talk from young males is a common challenge for many qualitative research studies (Bahn \& Barratt-Pugh, 2013). The implications of soliciting less detailed information from males in this sample is that results may be skewed towards the females' experiences; additional in-depth, qualitative research with reticent adolescent males of color on the topic of pornography use would enrich the findings of the present study. For males and females alike, social desirability may have influenced results; additional research that does not require youth to interact with a research assistant may produce richer results.

The results of this study face at least four limitations. First, inherent in qualitative research is the potential for those who collect or analyze data to introduce subjectivity and bias in the way that they pose questions, react to answers, or interpret quotations. We put substantial effort into reducing these potential sources of bias by developing and implementing a strict training protocol for data collection, using multiple coders for the content analysis, and ensuring that consensus was reached before codes were applied. Second, our sample was a convenience sample; participants in this study were not randomly selected from the population of youth in the city in which the research took place. This means that if there is something unique to emergency department patients who have viewed pornography that is not also true of the general population of youth, it could be that unmeasured factor influenced results. Third, there may be some who view the relatively small sample $(\mathrm{N}=23)$ as a limitation. In response, we would point out that the purpose of qualitative research is not to generate representative data; rather, it is to gather rich and detailed data that may give meaning to quantitative findings from other studies, or can be used to generate hypotheses for future research. Finally, some youth in this sample had viewed pornography relatively infrequently in the past year; $44 \%$ reported viewing it three to five times in the past 12 months (Table 1). It is reasonable to wonder if infrequent exposure could possibly influence youth attitudes or behaviors. However, both classical conditioning and priming theory support the contention that as little as one exposure to a particular stimulus could become imprinted and create a long-term arousal cue (Jo \& Berkowitz, 1994). As neurologists Ogas and Gaddam explain, "many male sexual obsessions appear to form after a single exposure, rather than after repeated pairings of neutral stimulus and an arousing stimulus" (Ogas \& Gaddam, 2011). A single or short-term exposure to a particular stimulus may activate an existing, unconsicous set of beliefs that are consistent with that stimulus (Jo \& Berkowitz, 1994); in other words, one viewing of a pornographic scene could reinforce latent sexual scripts or arousal cues.

In conclusion, this study enriches the exisiting literature on adolescent pornography use by presenting information about the pornography-related experiences of a sample of low- 
income, urban, youth of color. The results revealed that youth are learning how to have sex from pornography and imitating sex acts that they view in pornography, in some cases with adverse effects. Many Black and Hispanic youth may be seeking out videos that may portray problematic sexual scripts, which could negatively influence adolescent youth who are still relatively sexually inexperienced, in the process of becoming sexually socialized, and internalizing sexual scripts that are presented in media.

\section{REFERENCES}

Bahn S, Barratt-Pugh L. Getting reticent young male participants to talk: Using artefact-mediated interviews to promote discursive interaction. Qualitative Social Work. 2013; 12(2):186-199. doi: $10.1177 / 1473325011420501$.

Baumeister RF. Gender differences in erotic plasticity: The female sex drive as socially flexible and responsive. Psychological Bulletin. 2000; 126(3):347-374. doi: 10.1037/0033-2909.126.3.347. [PubMed: 10825779]

Baumgartner SE, Sumter SR, Peter J, Valkenburg PM, Livingstone S. Does country context matter? Investigating the predictors of teen sexting across Europe. Computers in Human Behavior. 2014; 34:157-164. doi: 10.1016/j.chb.2014.01.041.

Bleakley A, Hennessy M, Fishbein M, Jordan A. It Works Both Ways: The Relationship Between Exposure to Sexual Content in the Media and Adolescent Sexual Behavior. Media Psychology. 2008; 11(4):443-461. doi: 10.1080/15213260802491986. [PubMed: 20376301]

Bleakley A, Hennessy M, Fishbein M, Jordan A. Using the integrative model to explain how exposure to sexual media content influences adolescent sexual behavior. Health Education \& Behavior. 2011; 38(5):530-540. [PubMed: 21606378]

Braun-Courville DK, Rojas M. Exposure to Sexually Explicit Web Sites and Adolescent Sexual Attitudes and Behaviors. Journal of Adolescent Health. 2009; 45(2):156-162. doi: 10.1016/ j.jadohealth.2008.12.004. [PubMed: 19628142]

Brooks S. Hypersexualization and the dark body: Race and inequality among Black and Latina women in the exotic dance industry. Sexuality Research \& Social Policy: A Journal of the NSRC. 2010; 7(2):70-80.

Brown J, L'Engle K. X-Rated Sexual Attitudes and Behaviors Associated With US Early Adolescents' Exposure to Sexually Explicit Media. Communication Research. 2009; 36(1):129-151. doi: 10.1177/0093650208326465.

Brown JD, L'Engle KL, Pardun CJ, Guo G, Kenneavy K, Jackson C. Sexy media matter: Exposure to sexual content in music, movies, television, and magazines predicts black and white adolescents' sexual behavior. Pediatrics. 2006; 117(4):1018-1027. doi: 10.1542/peds.2005-1406. [PubMed: 16585295]

Carroll JS, Padilla-Walker LM, Nelson LJ, Olson CD, Barry CM, Madsen SD. Generation XXX Pornography acceptance and use among emerging adults. Journal of Adolescent Research. 2008; 23(1):6-30. doi: 10.1177/0743558407306348.

Dariotis JK, Sifakis F, Pleck JH, Astone NM, Sonenstein FL. Racial and Ethnic Disparities in Sexual Risk Behaviors And STDs During Young Men's Transition to Adulthood. Perspectives on Sexual and Reproductive Health. 2011; 43(1):51-59. doi: 10.1363/4305111. [PubMed: 21388505]

Day A. Getting the 'blues': the existence, diffusion and influence of pornography on young peoples' sexual health in Sierra Leone. Culture Health \& Sexuality. 2014; 16(2):178-189. doi: 10.1080/13691058.2013.855819.

Deardorff J, Tschann JM, Flores E, de Groat CL, Steinberg JR, Ozer EJ. Latino Youths' Sexual Values and Condom Negotiation Strategies. Perspectives on Sexual and Reproductive Health. 2013; 45(4):182-190. doi: 10.1363/4518213. [PubMed: 24165307]

Eisenman R, Dantzker ML. Gender and Ethnic Differences in Sexual Attitudes at a Hispanic-Serving University. Journal of General Psychology. 2006; 133(2):153-162. [PubMed: 16705908] 
Finer LB, Zolna MR. Unintended pregnancy in the United States: incidence and disparities, 2006. Contraception. 2011; 84(5):478-485. doi: 10.1016/j.contraception.2011.07.013. [PubMed: 22018121]

Gagnon, JH.; Simon, W. Sexual conduct: The social sources of human sexuality. Transaction Publishers; New Brunswick, NJ: 2005.

Gonzalez-Ortega E, Orgaz-Baz B. Minors' exposure to online pornography: Prevalence, motivations, contents and effects. Anales De Psicologia. 2013; 29(2):319-327. doi: 10.6018/analesps. 29.2.131381.

Gorman S, Monk-Turner E, Fish J. Free adult internet website: How prevalent are degrading acts? Gender Issues. 2010; 27:131-145.

Hald GM, Kuyper L, Adam PCG, de Wit JBF. Does Viewing Explain Doing? Assessing the Association Between Sexually Explicit Materials Use and Sexual Behaviors in a Large Sample of Dutch Adolescents and Young Adults. Journal of Sexual Medicine. 2013; 10(12):2986-2995. doi: 10.1111/jsm.12157. [PubMed: 23621804]

Hussen SA, Bowleg L, Sangaramoorthy T, Malebranche DJ. Parents, peers and pornography: the influence of formative sexual scripts on adult HIV sexual risk behaviour among Black men in the USA. Culture Health \& Sexuality. 2012; 14(8):863-877. doi: 10.1080/13691058.2012.703327.

Jo, E.; Berkowitz, L. A priming effect of media influences: An update. In: Bryant, J.; Zillmann, D., editors. Media Effects: Advances in Theory and Research. Lawrence Erlbaum Associates; Hillsdale, NJ: 1994. p. 43-60.

Jonsson LS, Priebe G, Bladh M, Svedin CG. Voluntary sexual exposure online among Swedish youth social background, Internet behavior and psychosocial health. Computers in Human Behavior. 2014; 30:181-190. doi: 10.1016/j.chb.2013.08.005.

Kaplan DL, Jones EJ, Olson EC, Yunzal-Butler CB. Early Age of First Sex and Health Risk in an Urban Adolescent Population. Journal of School Health. 2013; 83(5):350-356. doi: 10.1111/josh. 12038. [PubMed: 23517003]

Koh HK, Graham G, Glied SA. Reducing racial and ethnic disparities: the action plan from the department of health and human services. Health Aff (Millwood). 2011; 30(10):1822-1829. doi: 10.1377/hlthaff.2011.0673. [PubMed: 21976322]

Livingstone, S.; Bober, M. Economic and Social Resarch Council. London School of Economics and Political Science; London, UK: 2004. UK children go online: Surveying the experiences of young people and their parents.

Lofgren-Martenson L, Mansson SA. Lust, Love, and Life: A Qualitative Study of Swedish Adolescents' Perceptions and Experiences with Pornography. Journal of Sex Research. 2010; 47(6):568-579. doi: 10.1080/00224490903151374. [PubMed: 19731132]

Luder MT, Pittet I, Berchtold A, Akre C, Michaud PA, Suris JC. Associations Between Online Pornography and Sexual Behavior Among Adolescents: Myth or Reality? Archives of Sexual Behavior. 2011; 40(5):1027-1035. doi: 10.1007/s10508-010-9714-0. [PubMed: 21290259]

Ma CMS, Shek DTL. Consumption of Pornographic Materials in Early Adolescents in Hong Kong. Journal of Pediatric and Adolescent Gynecology. 2013; 26(3):S18-S25. doi: 10.1016/j.jpag. 2013.03.011. [PubMed: 23683822]

Marston C, Lewis R. Anal heterosex among young people and implications for health promotion: a qualitative study in the UK. BMJ Open. 2014; 4(e004996):1-6. doi:10.1136/ bmjopen-2014-004996.

Meston CM, Ahrold T. Ethnic, Gender, and Acculturation Influences on Sexual Behaviors. Archives of Sexual Behavior. 2010; 39(1):179-189. doi: 10.1007/s10508-008-9415-0. [PubMed: 18931901]

Miller-Young M. Putting hypersexuality to work: Black women and Illicit Eroticism in pornography. Sexualities. 2010; 13(2):219-235.

Morgan E. Associations between Young Adults' Use of Sexually Explicit Materials and Their Sexual Preferences, Behaviors, and Satisfaction. Journal of Sex Research. 2011; 48(6):520-530. doi: 10.1080/00224499.2010.543960. [PubMed: 21259151]

Mulya TW, Hald GM. Self-Perceived Effects of Pornography Consumption in a Sample of Indonesian University Students. Media Psychology. 2014; 17(1):78-101. doi: 10.1080/15213269.2013.850038. 
Noll JG, Shenk CE, Barnes JE, Haralson KJ. Association of Maltreatment With High-Risk Internet Behaviors and Offline Encounters. Pediatrics. 2013; 131(2):E510-E517. doi: 10.1542/peds. 2012-1281. [PubMed: 23319522]

Ogas, O.; Gaddam, S. A Billion Wicked Thoughts. Penguin Group; New York, NY: 2011.

Olmstead SB, Negash S, Pasley K, Fincham FD. Emerging Adults' Expectations for Pornography Use in the Context of Future Committed Romantic Relationships: A Qualitative Study. Archives of Sexual Behavior. 2013; 42(4):625-635. doi: 10.1007/s10508-012-9986-7. [PubMed: 22886349]

Peter J, Valkenburg P. Adolescents' Exposure to Sexually Explicit Internet Material and Notions of Women as Sex Objects: Assessing Causality and Underlying Processes. Journal of Communication. 2009; 59(3):407. doi: 10.1111/j.1460-2466.2009.01422.x.

Peter J, Valkenburg PM. The Use of Sexually Explicit Internet Material and Its Antecedents: A Longitudinal Comparison of Adolescents and Adults. Archives of Sexual Behavior. 2011; 40(5): 1015-1025. doi: 10.1007/s10508-010-9644-x. [PubMed: 20623250]

Pfaus JG, Kippin TE, Coria-Avila GA, Gelez H, Afonso VM, Ismail N, Parada M. Who, What, Where, When (and Maybe Even Why)? How the Experience of Sexual Reward Connects Sexual Desire, Preference, and Performance. Archives of Sexual Behavior. 2012; 41(1):31-62. doi: 10.1007/ s10508-012-9935-5. [PubMed: 22402996]

Pornhub.com. Pornhub's Top Search Terms in US Cities. 2014. Retrieved August 5, 2014, from http:// www.pornhub.com/insights/top-search-terms-usa-cities/

Rothman EF, Decker MR, Miller E, Reed E, Raj A, Silverman JG. Multi-person Sex among a Sample of Adolescent Female Urban Health Clinic Patients. Journal of Urban Health-Bulletin of the New York Academy of Medicine. 2012; 89(1):129-137. doi: 10.1007/s11524-011-9630-1. [PubMed: 22160481]

Rothman EF, Linden JA, Baughman AL, Kaczmarsky C, Thompson M. "The alcohol just pissed me off": Views about how alcohol and marijuana influence adolescent dating violence perpetration, results of a qualitative study. Youth \& Society. 2013

Sakaluk JK, Todd LM, Milhausen R, Lachowsky NJ. Dominant Heterosexual Sexual Scripts in Emerging Adulthood: Conceptualization and Measurement. Journal of Sex Research. 2014; 51(5): 516-531. doi: 10.1080/00224499.2012.745473. [PubMed: 23672338]

Sinkovic M, Stulhofer A, Bozic J. Revisiting the Association between Pornography Use and Risky Sexual Behaviors: The Role of Early Exposure to Pornography and Sexual Sensation Seeking. Journal of Sex Research. 2013; 50(7):633-641. doi: 10.1080/00224499.2012.681403. [PubMed: 22853694]

Smith M. Youth Viewing Sexually Explicit Material Online: Addressing the Elephant on the Screen. Sexuality Research and Social Policy. 2013; 10(1):62-75. doi: 10.1007/s13178-012-0103-4.

Stulhofer A, Jelovica V, Ruzic J. Is Early Exposure to Pornography a Risk Factor for Sexual Compulsivity? Findings from an Online Survey among Young Heterosexual Adults. International Journal of Sexual Health. 2008; 20(4):270-280. doi: 10.1080/19317610802411870.

Subero G. Gay Mexican pornography at the intersection of ethnic and national identity in Jorge Diestra's La Putiza. Sexuality \& Culture: An Interdisciplinary Quarterly. 2010; 14(3):217-233.

Trostle LC. Overrating pornography as a source of sex information for university students: Additional consistent findings. Psychological Reports. 2003; 92(1):143-150. doi: 10.2466/pr0.92.1.143-150. [PubMed: 12674273]

Tsitsika A, Critselis E, Kormas G, Konstantoulaki E, Constantopoulos A, Kafetzis D. Adolescent Pornographic Internet Site Use: A Multivariate Regression Analysis of the Predictive Factors of Use and Psychosocial Implications. Cyberpsychology \& Behavior. 2009; 12(5):545-550. doi: 10.1089/cpb.2008.0346. [PubMed: 19772438]

Wolak J, Mitchell K, Finkelhor D. Unwanted and wanted exposure to online pornography in a national sample of youth Internet users. Pediatrics. 2007; 119(2):247-257. doi: 10.1542/peds.2006-1891. [PubMed: 17272613]

Wright PJ. US Males and Pornography, 1973-2010: Consumption, Predictors, Correlates. Journal of Sex Research. 2013; 50(1):60-71. doi: 10.1080/00224499.2011.628132. [PubMed: 22126160] 
Wright PJ, Bae S, Funk M. United States Women and Pornography Through Four Decades: Exposure, Attitudes, Behaviors, Individual Differences. Archives of Sexual Behavior. 2013; 42(7):11311144. doi: 10.1007/s10508-013-0116-y. [PubMed: 23733153]

Ybarra ML, Mitchell KJ, Hamburger M, Diener-West M, Leaf PJ. X-Rated Material and Perpetration of Sexually Aggressive Behavior Among Children and Adolescents: Is There a Link? Aggressive Behavior. 2011; 37(1):1-18. doi: 10.1002/ab.20367. [PubMed: 21046607] 


\section{Table 1}

Descriptive statistics of the sample $(\mathrm{N}=23)$

\begin{tabular}{lccc}
\hline & $\begin{array}{c}\text { All participants } \\
(\mathbf{N}=\mathbf{2 3})\end{array}$ & $\begin{array}{c}\text { Females } \\
(\mathbf{n = 1 4})\end{array}$ & $\begin{array}{c}\text { Males } \\
(\mathbf{n = 9})\end{array}$ \\
\hline Sex & & & \\
Female & $60 \%(14)$ & $100 \%(14)$ & $0 \%(0)$ \\
Male & $40 \%(9)$ & $0 \%(0)$ & $100 \%(9)$ \\
& & & \\
Age (in years) & & & 17.6 \\
Mean & 17.6 & 17.6 & 18 \\
Median & 18 & 18 & $17-18$ \\
Range & $17-18$ & $17-18$ & \\
& & & \\
Race & & & \\
Black & $47 \%(11)$ & $50 \%(7)$ & $44 \%(4)$ \\
Hispanic & $43 \%(10)$ & $43 \%(6)$ & $44 \%(4)$ \\
Multiracial & $9 \%(2)$ & $7 \%(1)$ & $11 \%(1)$
\end{tabular}

Has ever had sexual intercourse

$\begin{array}{cccc}\text { Yes } & 100 \%(23) & 100 \%(14) & 100 \%(9) \\ \text { No } & 0 \%(0) & 0 \%(0) & 0 \%(0)\end{array}$

Currently has a girlfriend or wife, boyfriend or husband, sexual or hookup partner, or friends with benefits

Yes

No

The number of times in the past year the participant has seen or looked at pornography or X-rated material, including online, in a magazine, or video/cable

Mean number of times

Median number of times

Range

1-2 times

3-5 times

6-10 times

More than 10 times

$\begin{array}{ccc}100 \%(23) & 100 \%(14) & 100 \%(9) \\ 0 \%(0) & 0 \%(0) & 0 \%(0)\end{array}$

$\begin{array}{lll}47 & 14 & 99\end{array}$

$12 \quad 9 \quad 12$

3-730 3-52 4-730

$0 \%(0) \quad 0 \%(0) \quad 0 \%(0)$

$39 \%(9) \quad 50 \%(7) \quad 22 \%(2)$

$0 \%(0) \quad 0 \%(0) \quad 0 \%(0)$

$61 \%(14) \quad 50 \%(7) \quad 78 \%(7)$

Frequency of pornography watching reported by participants (on average in the past year)

Less than once a month

$39 \%(9) \quad 50 \%(7) \quad 22 \%(2)$

$39 \%(9) \quad 36 \%(5) \quad 44 \%(4)$

$17 \%(4) \quad 14 \%(2) \quad 22 \%(2)$

$0 \%(0) \quad 0 \%(0) \quad 0 \%(0)$ 


\begin{tabular}{cccc}
\hline & $\begin{array}{c}\text { All participants } \\
(\mathbf{N}=\mathbf{2 3})\end{array}$ & $\begin{array}{c}\text { Females } \\
(\mathbf{n = 1 4})\end{array}$ & $\begin{array}{c}\text { Males } \\
(\mathbf{n = 9})\end{array}$ \\
\hline Many times a day & $4 \%(1)$ & $0 \%(0)$ & $11 \%(1)$ \\
\hline
\end{tabular}

